\title{
The Relationship between Gender and Delinquency: Assessing the Mediating Role of Anticipated Guilt
}

\begin{abstract}
Purpose: Gender differences in delinquency are well-documented, with dominant explanations drawing largely on control, strain, and learning theories. We suggest that gender differences in guilt mediate a substantial portion of gender's association with delinquency over and above variables derived from these theories.

Methods: We use negative binomial regression and path analysis to test this assertion using data collected from a convenience sample of middle school and high school students in a Northeastern region of the United States.

Results: Results suggest that variables derived from control and learning theories may explain part of the gender gap in delinquency, but that a larger portion of the gender gap is due to gender differences in anticipated guilt.

Conclusions: Anticipated guilt appears to reflect a critical component of the explanation for why males engage in higher levels of delinquency than females, and future research should therefore pay greater attention to identifying the factors that influence interpersonal differences in the experience of guilt.
\end{abstract}

Key Words: Gender, Delinquency, Guilt 


\section{The Relationship between Gender and Delinquency: Assessing the Mediating Role of Anticipated Guilt}

Gender is perhaps the strongest predictor of criminal behavior, with males tending to exhibit both a higher prevalence and frequency of offending (Steffensmeier \& Schwartz, 2009). Gender differences in offending occur within all major sources of criminological data, including official, victimization, and self-report data (Lo \& Zhong, 2006; Steffensmeier, Schwartz, Zhong \& Ackerman, 2005). Such differences, however, vary significantly by offense and are most pronounced for serious and violent crimes. Given the very large gender difference in offending, it is essential that criminological theory account for the gender gap in crime.

Explanations of the gender gap in offending have largely emerged from mainstream criminology theories concerning learning, control, and strain. Most accounts suggest that males and females differ in their average levels of variables derived from these theories, but some suggest that these variables exert differential influences by gender. Learning theories (e.g., Akers, 2009) argue that males are more exposed to criminal role models, especially peers, and that these role models teach beliefs favorable to crime and differentially reinforce crime. Control theories (Hirschi, 1969; Gottfredson \& Hirschi, 1990) argue that males tend to experience lower levels of direct and indirect supervision, particularly in the context of the family (e.g. Hagan, Gillis \& Simpson 1990; Hagan, Simpson \& Gillis, 1987), resulting in lower levels of male constraint against crime. Males are likewise said to be less strongly attached to parents, less committed to school, and less likely to condemn crime (DeCoster, Heimer, \& Cumley, 2013). Strain theories account for the gender gap by suggesting that males experience higher levels of those strains conducive to offending, such as victimization or negative school experiences, and are more likely to cope with strains through crime (Agnew, 2006; Broidy \& Agnew, 1997). 
The present study does not deny these arguments, but directs attention to a potentially important cause of gender differences in offending that has received less emphasis by mainstream theories. A central theme in the larger gender literature, particularly the literature dealing with gender socialization, roles, and identity, is that, relative to males, females are taught to place more emphasis on the care and nurture of others, compassion for others, the maintenance of close interpersonal ties, and a passive/submissive interactional style (Gilligan, 1982; Lapsley, 1996; Messerschmidt, 1993). As a consequence, females should be less likely to engage in other-directed crime; in particular, the contemplation of crime should be more likely to provoke feelings of guilt in females than males. Data provide some support for this argument, suggesting that females are more likely to experience guilt than males (Else-Quest et al., 2012; Ferguson et al., 2000). But criminologists have largely neglected guilt when attempting to explain the gender gap in crime (although see Blackwell, 2000; Campbell, 2006; Eagly \& Steffen, 1986; Finlay \& Grasmick, 1985). This study contributes to the literature on the gender gap in offending by focusing explicitly on the extent to which controlling for anticipated guilt reduces the gap in offending over and above variables from the leading theories.

Below, we begin by elaborating upon mainstream explanations for the gender gap in offending and reviewing existing empirical research bearing on these explanations. We then discuss why females are more likely than males to experience guilt when contemplating or engaging in other-directed crime. Finally, we provide an empirical examination of the role that guilt plays in explaining the gender gap in crime. In particular, using multiple waves of panel data collected from middle- and high-school students who participated in the New Hampshire Youth Study, we examine (a) whether females and males report different average levels of criminal offending, (b) whether females report anticipating higher levels of guilt than males for 
prospective offenses, and (c) whether differences in anticipated guilt mediate a portion of the gender gap net of variables from mainstream theories of crime.

\section{Mainstream Accounts of the Gender Gap in Offending}

\section{Learning Theory}

According to learning theories, crime results from interactions with others who model criminal behavior, expose individuals to favorable beliefs about crime, and reinforce offending (Sutherland, 1947; Akers, 2009). According to this perspective, males' greater offending is thought to be based primarily on their greater exposure to delinquent others. Consistent with this framework, some research suggests that males are more likely than females to be exposed to delinquent peers and to hold beliefs that are favorable to delinquency (Heimer \& DeCoster, 1999; Jensen, 2003; Liu \& Kaplan, 1999; Mears, Ploeger, \& Warr, 1998). Research has further shown that gender differences in delinquent peer association and delinquent beliefs can explain a significant portion of the gender gap in delinquency (Bell, 2009; Jensen, 2003; Liu \& Kaplan, 1999; Mears, Ploeger \& Warr, 1998; Moffitt, Caspi, Rutter, \& Silva, 2001; Preston, 2006). With few exceptions (see Svensson, 2003), however, such studies have been unable to fully account for the gap between male and female delinquency.

Additional research has examined the degree to which higher male crime and delinquency reflect greater male exposure to positive reinforcement for such behavior. In particular, both genders face pressure to uphold stereotypes that dictate appropriate 'masculine' and 'feminine' behavior, including criminal behavior (see Messerschmidt, 1993; Heimer \& DeCoster, 1999; Jansz, 2000; Burt \& Clay-Warner, 2004; Mullins, Wright, \& Jacobs, 2004). Male identities are said to emphasize competitiveness, daring, and strength, while females' identities are said to emphasize empathy, caution, and submissiveness. Consistent with such 
arguments, masculine gender-role identity, or identification with stereotypically male roles, has been linked empirically to a higher likelihood of violent offending (Beesley \& McGuire, 2009) and aggressive intentions among males (Coleman, Goldman, \& Kugler, 2009). Further, research finds that males are more likely to view themselves in stereotypically masculine terms, that females are more likely to view themselves in stereotypically feminine ones, and that these differences in self-perception partially account for gender differences in delinquency (Jensen, 2003).

A final learning-based explanation for gender differences in crime and delinquency suggests that males and females are not only differentially exposed to definitions and reinforcements related to offending, but that they are differentially vulnerable to certain components of this learning process. Girls, for example, may be socialized to be more otherfocused and relationship-oriented than boys, resulting in a stronger influence of others' potential disapproval on female crime (Heimer, 1996; Zimmerman \& Messner, 2010). Using data from the National Youth Survey, Heimer (1996) found partial support for this assertion. Although some studies have shown that the influence of delinquent peers does not vary by gender (Alarid, Burton \& Cullen 2000; Moffitt et al. 2001; Smith \& Paternoster 1987), others have reported that delinquent peers better predict delinquency for males than females (Piquero, Gover, MacDonald, \& Piquero, 2005; Mears, Ploeger, \& Warr, 1998). Further, Mears et al. (1998) found that girls were more likely than boys to hold beliefs unfavorable to delinquency, and these differences largely accounted for the stronger influence of peer behavior on male versus female delinquency.

Although learning arguments do not focus specifically on guilt, they are compatible with the idea that guilt may help explain gender differences in crime. Females could be more likely than males to experience guilt at least partly for reasons described by social learning theory; they 
are more likely to learn beliefs and identities opposed to crime and are more likely to face consequences for violating "feminine" norms of behavior. The contemplation of crime would therefore be more likely to provoke guilt among females, acting as a major form of punishment and thus constraining their offending relative to males. Control Theory

In contrast to learning theory, control theory begins with the premise that crime often satisfies an individual's immediate self-interests and, therefore, that no extrinsic learning is necessary to motivate crime (Gottfredson \& Hirschi, 1990). Rather than attempting to identify social forces that promote the learning of crime, control theory identifies those social forces that constrain individuals' natural pursuit of immediate gratification. Control theories suggest that males have higher rates of offending than females because they have weaker social bonds to society, are subject to lower levels of external supervision or discipline among parents and other authority figures, and are therefore lower in self-control than their female counterparts (Costello \& Mederer, 2003; Gottfredson \& Hirschi, 1990; Heimer \& DeCoster, 1999).

Existing research provides partial support for social control theory explanations of the gender gap in crime. In comparison to females, for example, juvenile males tend to be less strongly attached to conventional others, less constrained from crime by peers, less committed or attached to conventional institutions like school, and less supervised by parents (Bottcher, 2001; Costello \& Mederer, 2003; Crosnoe, Erickson, \& Dornbusch, 2002; McCarthy, Felmlee, \& Hagan, 2004; Thornberry, Lizotte, Krohn, Farnworth, \& Jang, 1991). However, while research indicates that weaker social bonds among males may account for a portion of their greater delinquency, it does not suggest that these bonds can account fully for gender differences in offending (Bell, 2009; Booth, Farrell, \& Varano, 2008). The role of guilt has not been considered within social control arguments. 
Gottfredson and Hirschi's (1990) general theory of crime argues that consistent parental monitoring and sanctioning of inappropriate behavior promotes the development of self-control in early childhood. According to these theorists, interpersonal differences in self-control remain stable after the first decade of life and crime results when individuals low in self-control encounter criminal opportunities. By extension, Gottfredson and Hirschi's (1990) theory suggests that gender differences in crime reflect gender differences in parental discipline, such that girls are more consistently sanctioned for rule violations, thus leading them to develop higher levels of self-control than males. Some empirical evidence provides partial support for these assertions. Svensson (2003), for example, found that parental monitoring was significantly associated with juvenile drug and alcohol use, and that gender differences in these behaviors were significantly reduced when controlling for parental monitoring. Looking directly at the role of self-control in the gender gap, Burton, Cullen, Evans, Alarid, and Dunaway (1998) found that gender differences in a 20 -item scale of self-reported crime among adults were fully explained when self-control was included in the statistical model (see also Higgins \& Tewksbury, 2006; Moffitt et al., 2001; Tittle, Ward, \& Grasmick, 2003). However, other studies find that males are more likely to engage in both violence and property crime even when adjusting statistically for self-control (e.g., LaGrange \& Silverman, 1999; Kaplan \& Lui, 2006) and that parenting may continue to bear a significant relationship with offending even after adjusting statistically for self-control (Rebellon, Straus, \& Medieros, 2008). These results suggest that self-control provides an incomplete account of the gender gap in offending and, further, that direct controls like parenting may promote gender differences in offending over and above the mediating influence of self-control. 
Control arguments also have not assigned a central role to guilt in accounting for the gender gap, yet gender differences in both self-control and key bonds may correspond to gender differences in guilt. If females are monitored more closely and socialized into higher levels of attachment and belief than males, they should be more likely to experience guilt when engaging in or contemplating other-directed crime. An increased tendency to experience guilt in the face of wrongdoing could also function as a powerful internal control.

\section{Strain Theory}

In contrast to control theories, which imply that motivation for crime is constant across individuals, Agnew's general strain theory (GST) suggests that crime sometimes reflects an attempt to cope with various forms of environmental stress that promote negative emotion and create pressure for corrective action (Agnew, 1992; Agnew, 2006). Applying these ideas to the gender gap in crime, Broidy and Agnew (1997) acknowledge that much research actually finds higher levels of stress among females versus males, but argue that females may be less likely to react to a given strain with the types of outward-directed negative emotions (e.g., anger, frustration) that may promote crime and that males may experience higher exposure to the particular types of strain that are most likely to promote criminal coping. In this area, some research suggests that males are more likely to experience strains conducive to crime such as harsh parental discipline, conflict among peers, criminal victimization, and pressure to achieve a masculine identity (Agnew, 2006; Agnew \& Brezina, 1997; Bottcher, 2001; Broidy \& Agnew, 1997; Giordano, Cernkovich, \& Pugh, 1986; Hay, 2003; McCarthy, Felmlee, \& Hagan, 2004; Messerschmidt, 1993. Eitle and Turner (2002), for example, found that the gender gap could be partially explained by the greater exposure of males versus females to direct and vicarious experiences with violent victimization. In contrast, females may be more likely than males to 
experience other types of strain that constrain delinquent coping strategies, such as extremely close supervision, expectations to care for family members, and pressure to conform to feminine gender roles (Agnew, 2006; Agnew \& Brezina, 1997; Broidy \& Agnew, 1997). For the most part, however, research has not explored the extent to which such gender differences in the experience of various strains can account for the gender gap in offending (Agnew, 2009). In addition to experiencing different levels and types of strain, the social psychology literature suggests support for Broidy and Agnew's (1997) argument that males and females may differ in their emotional reactions to strain (see Brody \& Hall, 2000; Frost \& Averill, 1982; Jansz, 2000; Mirowsky \& Ross, 1995; Mirowsky \& Ross, 2003; Shields, 1995). Females are equally or more likely than males to experience anger (Campbell, 1993; Frost \& Averill, 1982; Mirowsky \& Ross, 1995), but females are also more likely to experience other forms of distress, such as depression, anxiety or guilt (Brody \& Hall, 2000; Campbell, 1993; Mirowsky \& Ross, $1995)$ in combination with anger. Whereas the experience of anger alone may facilitate the external attribution of blame for the strain that males typically experience, emotions like depression or anxiety may instead be more likely to promote internalized attributions of blame (Averill, 1983; Smith \& Lazarus, 1993; Thompson, 1999) that are less conducive to criminal coping (Broidy, 2001; Hay, 2003; Sigfusdottir, Farkas, \& Silver, 2004; Jang \& Johnson, 2005; Jang, 2007). Research further suggests that depression may increase the likelihood of deviant behavior (Piquero, Piquero, Capowich \& Mazerolle, 2010) and offending (Manasse \& Ganem, 2009; Ostowsky \& Messner, 2005) for males, but not for females, and that anger is a significantly stronger predictor of male offending than female offending (Baron, 2007; Piquero \& Sealock, 2004; Sigfusdottir et al., 2004). It is important to note, however, that while Broidy and Agnew (1997) explicitly identify guilt as an emotional response to strain that may both 
constrain criminal coping response and vary significantly by gender, empirical tests of GST have not examined the extent to which guilt accounts for gender differences in offending. Finally, limited research suggests that variables like social support and religiosity lower females' likelihood of responding to depression or anxiety with crime while variables like self-esteem and self-efficacy increase females' likelihood of coping with anger in non-criminal ways (Jang, 2007).

In sum, multiple factors associated with the leading crime theories have been used to explain the gender gap in crime. Although factors such as delinquent peer association, parental supervision, and self-control are able to account for a substantial portion of this gap, such factors are unable to account consistently for the gender gap in criminal offending (Agnew, 2009). We submit that a portion of the gender/crime association is attributable to sex differences anticipated guilt.

\section{The Role of Guilt in the Gender Gap}

Most theoretical accounts have paid insufficient attention to the role that gender differences in guilt may play in explaining the gender gap in offending. As a result, relatively few studies examine whether gender differences in guilt can explain the gender gap in offending. The limited attention to guilt as an explanatory factor for the gender gap in offending is unfortunate because preliminary research suggests guilt to be a viable, and potentially critical, component of a complete explanation for gender differences in crime. Guilt is generally conceived of as a negative emotion that results when an individual feels badly about one or more particular behaviors in which he or she has engaged (Tangney et al., 2007). Whereas the potentially related emotion of shame tends to connote an individual's negative feelings about his or her entire self-concept, the focus of guilt (and anticipated guilt) on discrete acts may have a 
particularly strong effect on offending. Research suggests that guilt or the anticipation of guilt has a major effect on the likelihood of crime (e.g., Blackwell, 2000; Campbell, 2006; Esbensen et al., 2010; Grasmick \& Bursik, 1990; Svensson, Weerman, Pauwels, Bruinsma, \& Bernasco, 2013; Tibbetts, 2003) and that females are more likely than males to experience guilt when contemplating crime (e.g., Blackwell, 2000; Campbell, 2006; Eagly \& Steffen, 1986; Finlay \& Grasmick, 1985; Grasmick et al., 1993).

As suggested above, the relationship between gender and guilt is most often explained in terms of gender differences in socialization and social position. Males, for example, are more often socialized to be tough, aggressive, assertive, and competitive, while females are more often socialized to be caring and concerned for the welfare of others (Gilligan, 1982; Lapsley, 1996; Messerschmidt, 1993). Consequently, multiple theorists predict that females who engage in other-directed crime or contemplate such crime may be more likely than males to experience guilt (Benetti-McQuoid \& Bursik, 2005; Blackwell, 2000; Finley \& Bursik, 1985; Eagly \& Steffen, 1986). Consistent with this notion, research suggests that males are less likely than females to believe they will experience negative consequences for crime, including both formal and informal sanctions (Eagly \& Steffen, 1986; Grasmick et al., 1993; Blackwell, 2000). Likewise, research suggests that females who hold traditional gender role beliefs are more likely than other females to anticipate guilt when contemplating crime (Finlay \& Gramsmick, 1985; also see Blackwell, 2000).

In addition to potentially explaining part of the relationship between gender and crime, however, guilt may explain a substantial part of the effect that key variables from the leading theories have on crime. For example, high levels of strain may help explain criminal behavior partly because high strain reduces concern for others, thus alleviating feelings of guilt (Agnew, 
2014). And as suggested above, variation in moral attitudes may help account for criminal behavior because those who internalize beliefs condemning crime are more likely to experience guilt when contemplating crime. Similarly, interactions with deviant peers may increase offending, in part, because without pressure to conform, juveniles are less likely to anticipate guilt. In fact, juveniles may anticipate feelings of guilt for conformity if deviant peers encourage criminal acts and mock or ostracize non-offenders (Warr, 2002). Likewise, the relationship between various control variables and offending may be associated with differences in guilt. For example, individuals may be more likely to anticipate guilt when contemplating crime if they care about conventional others (Blackwell, 1990; Finlay \& Grasmick, 1985; Grasmick et al., 1993) or are high in self-control. Those low in self-control tend to be preoccupied with personal needs, tend to have little concern for others, and tend not to give much thought to the consequences of their behavior. It follows, therefore, that they should be expected to experience less guilt upon the commission of crime or to anticipate less guilt at the prospect of committing crime. Indeed, Svensson et al. (2013) provides some support for these propositions, finding that variables like parental supervision, association with deviant peers, and moral values may influence crime partly via their influence on moral emotions.

Integrating many of the above assertions, Wikstrom's (2004; 2006) Situational Action Theory [SAT] proposes that criminological theory often fails to differentiate between direct and indirect effects, and that moral emotions, such as guilt or shame, are among the most proximate determinants of the decision to offend. Wikstrom emphasizes that crimes are moral actions, and whether or not an actor sees crime as a viable action depends on the actor's criminal propensity, defined largely as one's moral values/emotions and level of self-control, as well as how that propensity interacts with the moral rules and level of enforcement within a given environment. 
According to SAT, the motivation to offend will be guided largely by moral judgment, as individuals assess moral values and emotions (i.e. how guilty would I feel?) in comparison to the moral rules and potential consequences within the environment. Empirical tests of SAT support the proposition that morality is central to criminal acts (Antonaccio \& Tittle, 2008; Wikstrom \& Svensson, 2010; Wikstrom, Tseloni \& Karlis, 2011), although such tests tend to operationalize morality using only measures of moral values and have not yet addressed gender differences in offending.

\section{Summary}

In sum, both theory and research suggest that anticipated guilt may play a central role in the explanation of crime, may explain a substantial portion of the effect of other key causes on crime, and may help account for gender differences in crime. However, there has not been much research on the extent to which the gender gap in crime is explained by gender differences in guilt, despite the compatibility of such an argument with existing theoretical perspectives.

Certain psychological research suggests that gender differences in anticipated guilt may explain a substantial part of the gender gap in aggression (Eagly and Steffen, 1986), but the aggression in such research typically does not involve criminal behavior (e.g., it involves the administration of electric shocks in a laboratory setting). As yet, very limited criminological research includes explicit measures of guilt when examining the gender gap in offending, with such research yielding preliminary evidence that guilt explains a significant portion of the gap (Blackwell, 2000). This research, however, has not included measures for most of the other variables, like self-control or deviant peers, that are believed to play a key role in explaining the gender gap. As such, it does not allow us to properly estimate the direct role that guilt plays in accounting for the gender gap or the indirect role that it plays by mediating the effect of other variables. Below, we 
examine these issues using primary data collected from a community sample of middle-school and high-school youth.

\section{Methods}

Data

We collected data for the present study in the fall of 2007, the spring of 2008, and the fall of 2008 from students in eight middle-schools and five high-schools throughout southern New Hampshire. Respondents consist of all students from these schools who were in the $7^{\text {th }}$ or $10^{\text {th }}$ grade in the 2007-2008 academic year and whose parents gave permission for their children to participate in our confidential survey study. Surveys generally required 30-45 minutes to complete. A total of 941 respondents completed a survey in the fall of 2007 , representing $23 \%$ of all students enrolled in any of the 13 schools. Of these 941 , two did not identify their grade level. Of the remaining $939,52.5 \%$ were in 7 th grade and $46 \%$ were in 10 th grade. The remaining $1.5 \%$ were one grade above or below their peers. A total of 936 participants provided their age in the fall of 2007, with ages ranging from 11-17 $(\mathrm{M}=13.7, \mathrm{SD}=1.6)$. A total of 938 respondents reported their gender in the fall of 2007 , with $41.6 \%$ being males and $58.4 \%$ being females (for further details, see Cohn et al. 2010).

\section{Measures}

Delinquency and Drug Use. Our study uses delinquency measures and drug use measures collected in the fall of 2008, subsequent to the measurement of all our predictor variables. Our delinquency measure is a nine-item index reflecting how many of nine delinquency items a given respondent reported engaging in at least once over the course of the preceding six-month period.

Our drug use measure is a four-item index reflecting how many of four different drug-related behaviors individuals engaged in during the same period. Particular items for all indexes and 
scales appear in in Appendix A, while descriptive statistics for all indexes and scales, disaggregated by gender, appear in Table 1. All indexes reflect the number of applicable items that a given respondent endorsed and all scales reflect the mean of their constituent items.

(Table 1 about here)

Demographics. We measured gender as a dummy-coded variable ( $0=$ Male, $1=$ Female $)$ and measured age in years, with responses ranging from 11-17. Given that many youth did not know their parents' incomes, we use parental education as a proxy for socioeconomic status. We measured parental education separately for mother (or female guardian) and father (or male guardian) (1=less than high school, 2=high school diploma, 3=some college, 4=associate's degree, $5=$ bachelor's degree, $6=$ graduate or professional degree). For youth with one guardian, we use that guardian's education as our SES measure. For youth with two guardians, we use the mean of their education as our SES measure. Finally, we asked respondents to describe their racial or ethnic background and constructed a dummy variable to control for race $(1=$ white, $0=$ non-white).

Strain. We include four measures derived from Agnew's $(1992,2006)$ general strain theory and collected in the spring of 2008. The first is five-item scale reflecting respondent perceptions of how fairly parents, teachers, and peers treated them over the course of the preceding six-month period $(0=$ very fair, $1=$ somewhat fair, $2=$ somewhat unfair, $3=$ very unfair $)$. The second is a 14-item index reflecting the number of stressful life events, from a provided list, that respondents reported having experienced over the course of the preceding six-month period. Examples include "parental divorce/separation" and "romantic break-up." The third is a measure of anger. Of note, our anger measure is not trait-based (i.e., tending to have a bad temper), because such measures may be as theoretically reflective of low self-control as of strain. Rather, 
it is a five-item measure of situational anger reflecting how often respondents reported having been angry with parents, teachers, and peers in the preceding six-month period $(0=n e v e r, 1=a$ few times, $2=$ once or twice a month, $3=$ once or twice a week, $4=$ almost every day). The fourth is a 15-item depression scale derived from the CES-D (Radloff, 1977) and reflecting how often respondents reported having felt various depressive symptoms over the course of the preceding six-month period ( $0=$ not at all, $1=$ occasionally, $2=$ frequently, $3=$ almost all the time). Examples include "felt I was a failure" and "felt sad." While these measures do not include every type of strain that potentially differs by gender (for an overview, see Broidy \& Agnew, 1997), they include many elements of those strains that this literature has highlighted (e.g., school failure, victimization) as well as two separate measures of emotion (i.e., anger and depression) that this literature suggests to be gendered.

Control. We include four measures derived from control theory. The first, measured in the fall of 2007, is a 25 -item index reflecting how many types of rules (from a given list, which we have included in the Appendix) each respondent reported her/his parents to have set for her/him. Examples include rules about "what time you come home" and "drinking alcohol." Respondent scores for this index reflect how many different types of rules (from the list of 25 rule categories) a respondent reported that his or her parents have set for him or her. The second control measure, collected in the spring of 2008 , is a six-item scale reflecting indirect parental monitoring of respondent activities. In particular, it reflects the degree to which a respondent's parents tended to know their child's whereabouts, plans, and companions during the time that the respondent spent outside of school and outside of the household. Examples include "how often do parents ask where you are going?" and "If you'll be home late are you expected to call your parents?" (1=rarely, $2=$ sometimes, $3=$ =usually, $4=$ always). The third, measured in the fall of 2007 , 
is a scale reflecting the degree to which youth perceive that their parents enforced rules with consistent consequences. Examples include "If my parents tell me to do something they mean it" and "If my parents find out I disobeyed them, there are definitely consequences" (1=strongly agree, $2=$ agree, $3=$ disagree, $4=$ strongly disagree). The fourth, also measured in the fall of 2007 , is the 24-item Grasmick et al. (1993) self-control scale, reflecting the degree to which respondents report that they are impulsive, have a bad temper, tend to be selfish, prefer physical over mental tasks, like to take risks, and are averse to difficult tasks. Although our data do not allow us to measure certain sources of social control (e.g., parental attachment and school commitment), such measures have not been found to explain the entire gender gap in prior research (Bell, 2009; Booth et al., 2008) and our data do allow for a fuller test of self-control explanations of the gender gap than prior research has yet provided.

Learning. We include four scales, measured in the fall of 2007, reflecting key aspects of social learning. The first two reflect peer behavior in the six months prior to data collection. In particular, we asked respondents to report the proportion of their friends that they believed to have engaged in each of the delinquency and drug use behaviors from our delinquency and drug use indexes ( $0=$ none, $1=\mathrm{a}$ few, $2=$ some, $3=$ many), yielding a nine-item peer delinquency scale and a four-item peer substance use scale. The second two learning scales reflect respondent approval of each behavior in our delinquency and drug use indexes ( $0=$ strongly disapprove, 1=disapprove, $2=$ approve, $3=$ strongly approve), yielding a nine-item delinquency approval scale and a four-item drug use approval scale.

Guilt. Our data include four items, measured in the Fall of 2007, based on the question: "how guilty would you feel if you engaged in the following behavior, even if nobody found out?" We conceive of these measures as anticipated guilt. The four behaviors for which we 
measured anticipated guilt were theft of something worth less than five dollars, theft of something worth more than fifty dollars, punching someone who had not hit you first, and smoking marijuana ( $1=$ not at all guilty, $6=$ very guilty). We use the mean of the first three items to construct a scale reflecting anticipated guilt for delinquency and the fourth item as an indicator reflecting anticipated guilt for drug use. We note that our data do not include measures of guilt for all of the behaviors included in our delinquency index. Nonetheless, principal components analysis of the three items reflecting anticipated guilt for delinquency yielded one factor, with individual item loadings that all exceeded .85 , thus suggesting that these three items are indicators of a general and unidimensional underlying construct.

\section{Analytic Strategy}

Our analyses proceed in six steps. First, we compare mean levels of delinquency and drug use among males and females to determine whether our data yield significant gender differences to be explained. We note that our delinquency items reflect other-direct behaviors while our drug use items do not. Given that the gender literature we cite above suggests females to be more concerned with others than males, we anticipate greater gender differences in delinquency and delinquency-related guilt than in drug use or drug-related guilt. Second, we examine whether any such differences remain statistically significant in a baseline negative binomial regression analysis that controls for age, socioeconomic status, and race. Third, we examine the degree to which the gender coefficient from the baseline model diminishes in magnitude upon controlling in a series of separate negative binomial models for strain (Model 2), control (Model 3), learning (Model 4), and guilt (Model 5). While we do not measure all of the leading control, social learning, and strain variables, we measure most of them, including those variables that prior research suggests to account for the largest portion of the gap: parental supervision, delinquent 
peer association, and self-control. ${ }^{\mathrm{i}}$ Fourth, we examine the degree to which each predictor remains statistically significant upon controlling for other predictors (Models 6 and 7). ${ }^{\text {ii }} \mathrm{We}$ evaluate a variable's viability as a mediator of the gender/delinquency relationship on the basis of the following criteria: (a) the variable differs significantly by gender in the theoretically expected direction (see Table 1); (b) the variable is a significant predictor of delinquency after adjusting for covariates; and (c) including the variable in multivariate analysis lowers the magnitude of the gender coefficient in comparison to its Model 1 magnitude. Fifth, we disaggregate our final two models by gender to examine whether males and females differ in their "vulnerability" to the influence of one or more predictor variables (Models 8-11). Sixth, we attempt to replicate our negative binomial results via path analysis in Lisrel 8 and use Sobel tests (MacKinnon et al., 1995) based on raw estimates and their associated standard errors to further evaluate potential mediators of the relationship between gender and delinquency.

\section{Results}

Table 1 demonstrates that females report significantly lower delinquency, but not drug use, than do their male counterparts. We therefore focus our multivariate analyses on delinquency, where there exists a gender gap to be explained. We note, however, that the absence of a significant gender difference in our drug use measure is paralleled by the absence of a significant gender difference in anticipated guilt for drug use. These bivariate results for drug use are therefore consistent with the notion that gender differences in behavior exist only where there are parallel gender differences in anticipated guilt. Given that our delinquency measure is a count reflecting the variety of offenses in which respondents report engaging, Table 2 depicts the results of eleven negative binomial regression analyses (see Long, 1997) examining the degree to which gender remains significantly associated with delinquency upon adjusting for controls. 
Model 1 reveals a significant and positive association between age and delinquency, as well as a significant and negative association between socioeconomic status and delinquency. Net of these associations, Model 1 suggests that females remain significantly less delinquent than their male counterparts.

(Table 2 about here)

Turning to our assessment of alternative theoretical explanations for the gender difference in delinquency, we begin by evaluating whether our four strain variables mediate the gender/delinquency relationship. On one hand, males and females report statistically equivalent perceptions of unfairness, stressful life events, and anger. Because these variables do not differ significantly across gender, they cannot explain gender differences in delinquency. On the other hand, Table 1 does reveal a significant difference in depression across gender such that females report significantly more depression. At the same time, Model 2 fails to yield evidence of a significant relationship between depression and delinquency. Most importantly, however, none of the four strain variables meets our third criterion for mediation. In particular, although three of our four strain variables are significantly associated with delinquency in the anticipated directions, the magnitude of the gender coefficient in Model 2 is actually higher than is the corresponding coefficient from Model 1. Thus, while we find clear support for the notion that strain contributes to delinquency, we find no evidence that strain explains gender differences in delinquency.

Results do, however, suggest that variables derived from control theory may explain part, but not all, of the relationship between gender and delinquency. Although parental rules and consequences do not differ significantly by gender, Table 1 demonstrates that informal parental monitoring and self-control are significantly higher among female respondents compared to 
males. The latter two variables therefore meet our first criterion for mediation of the genderdelinquency relationship. Further, Table 2 reveals that these variables are associated with delinquency in the directions anticipated by control theory. These variables thus meet the second criterion for mediation. Most critically, although the Model 3 gender coefficient remains statistically significant even after adjusting for control theory variables, its magnitude is less than half of the corresponding magnitude in Model 1. Our parental monitoring and self-control variables therefore meet all three of our mediation criteria. These results, in turn, are consistent with the notion that females are less delinquent than males partly because they are more closely monitored and possess higher levels of self-control.

Results are similarly consistent with the notion that variables derived from learning theory explain part, but not all, of the relationship between gender and delinquency. Table 1 demonstrates that peer delinquency and delinquent attitudes are both lower among females in our sample compared to males, thus meeting our first criterion for mediation. Further, Table 2 demonstrates that both variables are significantly associated with delinquency, thus meeting our second criterion for mediation. Most importantly, although the Model 4 gender coefficient remains significantly associated with delinquency after adjusting statistically for both learning variables, its magnitude is less than half of the corresponding magnitude from Model 1. Variables derived from social learning theory therefore meet all three criteria for mediation. These results, in turn, are consistent with the notion that females are less delinquent in part because they are less prone to associate with delinquent peers and less likely to endorse delinquent attitudes.

Notwithstanding partial support for control and learning explanations of the relationship between gender and crime, Models 3 and 4 from Table 2 suggest that neither theory is capable of 
explaining the entire gender/delinquency relationship in our data. Further results from Tables 1 and 2, however, suggest that anticipated guilt may go a long way toward explaining the remainder of the relationship between gender and delinquency. In particular, Table 1 demonstrates that females report significantly higher levels of anticipated guilt at the prospect of engaging in delinquent behavior. Anticipated guilt therefore meets our first criterion for mediation of the gender/delinquency relationship. In addition, Table 2 demonstrates that our measure of anticipated guilt is significantly associated with delinquency in Model 5. By itself, guilt decreases the Model 1 magnitude of the gender/delinquency relationship to a greater degree (57.4\%) than do variables derived from control theory $(47.5 \%)$ or learning theory $(50.8 \%)$. On its own, in fact, our anticipated guilt measure not only meets all three criteria for mediation of the gender-delinquency relationship, but also lowers the gender coefficient to non-significance.

Although the first five models in Table 2 suggest compelling evidence that anticipated guilt may be a critical factor linking gender with delinquency, a truly rigorous test of this variable's mediating influence should address two further issues. First, notwithstanding Gottfredson and Hirschi's (1990) argument that control and learning theory are incompatible on account of their ostensibly different assumptions about human nature, it may be the case that variables derived from control and learning theory might collectively be capable of accounting for the entire gender/delinquency relationship. Second, it remains possible that the relationship between anticipated guilt and delinquency is spurious, reflecting their shared association with variables derived from control and learning theory. Models 6 and 7 in Table 2 address each of the above two issues.

With respect to the first issue, Model 6 includes each of our strain, control, and learning scales as simultaneous predictors of delinquency. Results reveal that life events, anger, parental 
monitoring, low self-control, peer delinquency, and delinquent attitudes remain independently associated with delinquency to a statistically significant degree. Net of these associations, however, results of Model 6 further reveal that a significant relationship remains between gender and delinquency. On one hand, the lower log-likelihood of Model 6 vis-à-vis Models 1-5 suggests that an integrated model including variables from strain, control, and learning theory provides a better explanation of individual differences in delinquency than do theory-specific models. On the other hand, however, Model 6 simultaneously suggests that variables from strain, control, and learning theory remain collectively incapable of explaining the entire gender/delinquency relationship.

With respect to the second issue, Model 7 incorporates all variables derived from strain, control, and learning theory, but simultaneously includes our measure of anticipated guilt as an independent predictor. Three results merit particular attention. First, although the magnitude of the coefficient linking anticipated guilt with delinquency is slightly less than half the corresponding coefficient in Model 5, it nonetheless remains statistically significant $(\mathrm{p}<.01)$. This suggests that anticipated guilt is an important variable independent of its potential association with variables derived from strain, control, and learning theory. Second, the loglikelihood in Model 7 diminishes in comparison to that of Model 6, further suggesting that anticipated guilt adds predictive power over and above that related to strain, control, and learning variables. Third, upon including anticipated guilt as a predictor in Model 7, the gender coefficient is no longer statistically significant, thus suggesting that anticipated guilt plays a critical role in explaining the gender/delinquency relationship over and above the role of control and learning variables. 
Whereas the above analyses focus on evaluating explanations of the gender/sdelinquency relationship based in differential male versus female exposure to risk and/or protective factors, it might also be the case that males and females are differentially vulnerable to the effects of the variables from Model 7. To explore this possibility empirically, Models 8-11 in Table 2 disaggregate the Model 7 analysis by gender. Models 8 and 9 assess gender differences in coefficients linking strain, control, and learning variables to delinquency before adjusting for guilt, while models 10 and 11 add guilt as a covariate. Several results are notable. First, delinquency is significantly associated with parental monitoring and anticipated guilt across gender. Second, peer delinquency is significantly associated with male delinquency, but falls short of predicting female delinquency to a statistically significant degree. While this might be interpreted as preliminary evidence that higher male delinquency reflects higher vulnerability to the influence of peer behavior, the z-scores comparing male and female peer delinquency coefficients are not significant (see Paternoster et al., 1998). This suggests that the association of peer delinquency with personal behavior does not differ significantly across gender. Third, life events are significantly associated with male, but not female, delinquency. This suggests preliminary evidence that higher male delinquency may be due partly to greater male vulnerability in the face of stressful life events. At the same time, the z-scores comparing the male and female coefficients fall shy of statistical significance, thus suggesting reason to question whether vulnerability to stressful life events provides an adequate explanation of the gender/delinquency relationship. Fourth, perceived injustice is significantly related to female, but not male, delinquency in models 10 and 11 . Further, the z-score comparing male and female coefficients for perceived injustice in these models is statistically significant. The positive valence of the perceived injustice coefficient for females, however, suggests that equal levels of 
perceived injustice should contribute to more, not less, female delinquency. Given that females are less delinquent, results do not suggest that the significantly higher vulnerability of females to the effect of injustice can logically explain why females are less delinquent than males.

As a means of attempting to replicate our negative binomial results while simultaneously gauging the relative mediating influence of guilt more precisely, we supplement the above analyses by estimating two path models via the Lisrel 8 (Joreskog and Sorbom, 1993) statistical package. The first omits our anticipated guilt variable, while the second incorporates it. Both models include all other predictors that were independently significant in Model 7 from Table 2. In addition to estimating each of these variables' direct associations with delinquency, our path models include gender as a direct predictor of delinquency. Likewise, however, they estimate gender's indirect association with delinquency via those variables that differed significantly by gender in Table 1. We omit estimates linking gender to anger or life-events in part because these variables were not significantly related to gender in bivariate analyses from Table 1, and in part to prevent our path model from being fully saturated (i.e., lacking degrees of freedom with which to calculate fit statistics). In order to account for high positive skew in our count measure of delinquency, we first collapsed all delinquency response categories that included less than five percent of our sample, yielding a delinquency measure with four categories. These categories reflected whether a given respondent reported engaging in $0,1,2$, or $3+$ types of delinquency during the six months prior to our fall 2008 data collection. Using polychoric correlations and their associated weight matrices, we then estimated our path models via Lisrel's weighted-leastsquares algorithm.

Figures 1 and 2 depict the results of our path models. Beginning with Figure 1, several results are noteworthy. First, four of our five direct predictors of delinquency are statistically 
significant. Second, gender is significantly associated with parental monitoring, self-control, and peer delinquency in the directions anticipated by control and learning theory. Finally, net of other variables in the model, gender remains significantly associated with delinquency in the expected direction. Turning to Figure 2, self-control, anger, and life events remain significantly associated with delinquency. Net of these variables, higher levels of anticipated guilt are significantly associated with lower delinquency. Sobel tests (MacKinnon et al., 1995) based on the raw coefficients and standard errors reported in Figure 2 suggest that guilt $(\mathrm{z}=-3.28)$ and low selfcontrol $(\mathrm{z}=-2.37)$ significantly mediate a portion of the relationship between gender and offending but that parental monitoring $(\mathrm{z}=-1.27)$ and differential association $(\mathrm{z}=-1.90)$ do not. Based on the standardized coefficients corresponding to the raw coefficients in Figure 2, the indirect association of gender with delinquency through guilt $\left(|.31|^{*} .|-29|=.09\right)$ is three times as large as the corresponding association through self-control $\left(|-.22|^{*} \cdot|15|=.03\right)$, which is the only other variable that our data suggest to differ significantly by gender while simultaneously being significantly associated with delinquency. Most importantly, upon including anticipated guilt in the path model, the direct association between gender and delinquency is no longer significant. Results of our path analyses thus suggest further evidence supporting the independent importance of anticipated guilt for fully explaining the gender/delinquency relationship.

\section{Discussion}

Gender is perhaps the strongest correlate of crime, but existing research has yet to provide a full explanation for the difference between male and female offending. The present study has argued that gender differences in the experience of guilt provide a critical, but largely unexplored, component of the complete explanation for the relationship between gender and delinquency. It likewise subjected this notion to empirical testing with a community sample of 
middle-school and high-school youth. Results replicate the long-standing finding that gender is significantly related to moderately severe forms of delinquency while bearing little relation to substance use (see Smith \& Visher, 1980). Consistent with a guilt-based explanation of gender differences in offending, results further reveal that females report significantly higher levels of anticipated guilt for delinquency, but not for substance use. Multivariate analyses using two separate estimation methods suggest that variables derived from mainstream accounts of the relationship between gender and crime explain a portion of that relationship, but that adding anticipated guilt to multivariate models is necessary for lowering gender coefficients to statistical non-significance.

While a limited number of prior studies have examined the degree to which moral emotions like guilt might shed light on the nature of the relationship between gender and crime, the present study is noteworthy for the range of variables that it includes from multiple mainstream criminological theories. Drawing on learning theory, it incorporates statistical adjustments for both delinquent peer exposure and delinquent definitions (i.e., attitudes), with results unveiling significant gender differences in both constructs. Multivariate results reveal that guilt remains a statistically significant predictor of delinquency even after adjusting for both measures, that guilt explains more of the gender difference in delinquency than both learning measures combined, and that guilt in fact appears to mediate the entire relationship between definitions and delinquency. Drawing on control theory, the present study further incorporates statistical adjustments for parental rules, monitoring, sanctioning, and self-control. While results are consistent with theoretical predictions that parents are more prone to monitor daughters and that daughters report higher self-control versus sons, guilt remains a significant predictor of delinquency independent of these variables and again does a better job of explaining gender 
differences in delinquency than these alternative variables. Finally, the present study incorporates a variety of measures derived from strain theory, including a standard measure of negative life events, a rare measure of unfair treatment, which Agnew (2006) has argued to be among the most crime-provoking strains, and two situational (as opposed to trait-based) measures of negative emotion. Guilt again remained significantly related to delinquency net of these variables and does a better job of explaining gender differences than all four of these strain measures combined. Overall, results reveal that guilt was capable of reducing the gender coefficient to non-significance even as all variables derived from the above three theories could not do so in combination.

Beyond their implications for the importance of guilt in explaining gender differences in offending, results echo previous findings in suggesting that the effects of key learning and control variables on offending are partly mediated by moral emotions like guilt/shame (Svensson et al., 2013). They therefore suggest that mainstream criminological theory should more explicitly consider the role of moral emotion in offending. Unlike most criminological theory, Wikstrom's (2004; 2006) Situational Action Theory (SAT) includes moral emotions like guilt and shame in its fundamental model of offending. In particular, it suggests that individual morality, which interacts with self-control to determine one's criminal propensity, is made up of both moral values and moral emotion. Certainly, both learning and control arguments suggest that moral values matter, whether conceived as definitions favorable to crime or as the belief that offending is wrong. Yet emotional responses to violating those moral values are not equally emphasized in many mainstream accounts of offending. Perhaps as a result, they are largely absent among existing empirical models of offending. At the same time, emotion is central not only as a potential constraint against offending in SAT, but also as a motivation for offending in 
General Strain Theory (GST). Further, a growing body of research incorporating elements of both SAT and GST has shown that experiencing non-angry emotions along with anger may constrain offending (Broidy, 2001; Hay, 2003; Sigfusdottir, Farkas, \& Silver, 2004; Jang \& Johnson, 2005; Jang, 2007). The present study provides only indirect support for such findings but suggests that future research should incorporate measures of guilt, as both a mediating state emotion and as a conditioning variable. Further, even to the degree that control theory views guilt as an extension of the belief that offending is wrong (Hirschi, 1969) or that learning theory views guilt as an element of the reinforcement process (Akers, 2009), theorists from both camps could provide more useful guidance to policy-makers by elaborating more explicit hypotheses about what specific social stimuli are most or least likely to increase or decrease guilt.

While our results provide what we believe to be strong evidence that gender differences in guilt play a (if not the) critical role in explaining gender differences in delinquency, they nonetheless leave important questions unanswered. First, given the convenience sample that we have used in our analyses, questions remain as to the generalizability of our findings. We should note that critical variables like peer delinquency, delinquent definitions, and self-control were all related to delinquency in our sample as should be expected based on prior research using more representative data. We have no reason to suspect that the relationship between guilt and delinquency in our data is somehow unique to our sample even as these other relationships resemble those occurring among adolescents writ large. Nonetheless, further research using more representative samples is in order to more rigorously establish the generalizability of our results. Likewise, further research should include measures of parental and school bonding, as well as additional measures of strain that were not available in our data. 
Second, our data speak little to the potential origins of gender differences in guilt. The addition of guilt to multivariate analysis reduces the magnitudes of those coefficients linking delinquency to parental monitoring, self-control, peer delinquency, and delinquent definitions. This suggests that guilt may mediate at least part of the relationship that each of these variables bears with delinquency and, by extension, that each of these variables may contribute to interpersonal differences in anticipated guilt. In particular, anticipated guilt may be partly a function of parental monitoring, self-control, peer delinquency, and delinquent definitions. Yet multivariate results suggest that anticipated guilt does not mediate the vast majority of the latter three variables' associations with delinquency. Further, even to the degree that anticipated guilt mediates the entire relationship between delinquent definitions and behavior, the exact sources of delinquent definitions in the present study remain empirically unidentified. In addition to replicating the present results with more representative samples, therefore, further research would do well to investigate the precise origins of gender differences in anticipated guilt.

While it is beyond the scope of the present study to elaborate a detailed theory concerning the origins of gender differences in guilt, we submit that any such theory would do well to incorporate three critical observations. First, biological factors are likely relevant. Hormone levels, for example, appear to differ in the aggregate across sex, to be associated with antisocial behavior, and to impinge upon emotional experience (e.g., Shirtcliff, Vitacco, Graf, Gostisha, Merz, \& Zahn-Waxler, 2009; Udry, 2000). Second, biological theorizing is neither hostile to, nor dismissive of, environmental factors (e.g., Buss \& Schmitt, 2011; Udry, 2000; Wade, 2013). Rather, biologically-informed theories generally speculate about various ways in which biological and social factors interact. Kemper's (1987:263) theory of emotion, for example, suggests that primary emotions like fear have largely biological origins, but that "guilt 
is a socialized response to arousal of the physiological conditions of fear." Similarly, Udry's (2000: 443) theory of gender suggests that "hormone experiences can facilitate or dampen the effects of socialization and environment on gendered behavior." Third, biological factors do not appear to exert a unidirectional influence on social or behavioral outcomes. A complete understanding of gender and crime will need to account for the ways in which power and status dynamics in the social environment are reciprocally-related to biological variables like hormone levels across the life-course (e.g., Kemper \& Collins; Udry, 2000) and across generations (e.g., Kemper, 1990). As a field that tends to view a particular issue from multiple perspectives rather than apply one perspective to multiple issues (Agnew, 2011), criminology is uniquely positioned to produce theory and research incorporating each of these observations. 


\section{References}

Adler, F. (1975). Sisters in Crime: The Rise of the New Female Criminal. New York, NY: McGraw-Hill.

Agnew, R. (1992). Foundation for a general strain theory of crime and delinquency. Criminology, 30, 47-87.

Agnew, R. (2006). Pressured into crime: An overview of general strain theory. Los Angeles: Roxbury.

Agnew, R. (2011). Toward a unified criminology: Integrating assumptions about crime, people and society. New York: NYU Press.

Agnew, R. (2009). The contribution of "mainstream" theories to the explanation of female delinquency. In M.A. Zahn (Ed.), The Delinquent Girl (pp. 50-83). Philadelphia, PA: Temple University Press.Akers, R. (1985). Deviant Behavior: A Social Learning Approach. Belmont, CA; Wadsworth.

Agnew, R. (2014). Social concern and crime: Moving beyond the assumption of simple selfinterest. Criminology, 52(1):1-32.

Agnew, R. \& T. Brezina. (1997). Relational problems with peers, gender, and delinquency. Youth and Society, 29: 84-111.

Akers, R. L. (2009). Social Learning and Social Structure: A General Theory of Crime and Deviance. Piscataway, NJ: Transaction Publishers.

Alarid, L. F., V. S. Burton, \& F. T. Cullen. (2000). Gender and crime among felony offenders: Assessing the generality of social control and differential association theories." Journal of Research in Crime and Delinquency 37: 171-199.

Antonaccio, O. \& Tittle, C. R. (2008). Morality, self-control, and crime. Criminology, 46, 2: 479-510.

Averill, J. R. (1982). Anger and Aggression: An Essay on Emotion. New York: Springer-Verlag.

Averill, J. R. (1983). Studies on anger and aggression: Implications for theories of emotion. American Psychologist, 38, 1145-1160.

Baron, S. W. (2007). Street youth, gender, financial strain, and crime: Exploring Broidy and Agnew's extension to general strain theory. Deviant Behavior, 28, 273-302.

Beesley, F., \& McGuire, J. (2009). Gender-role identity and hypermasculinity in violent offending. Psychology, Crime, and Law, 15, 251-268. 
Bell, K. E. (2009). Gender and gangs: A quantitative comparison. Crime \& Delinquency 55: 363387.

Benetti-McQuoid, J. \& Krisanne Bursik. (2005). Individual differences in experiences of and responses to guilt and shame: Examining the lenses of gender and gender role. Sex Roles 53(1/2):133-142.

Blackwell, B. S. (2000). Perceived sanction threats, gender, and crime: A test and elaboration of power-control theory. Criminology 38: 439-488.

Blackwell, B. S., C. S. Sellers, \& S. M. Schlaupitz. (2002). A power-control theory of vulnerability to crime and adolescent role exits-Revisited. The Canadian Review of Sociology and Anthropology 39 (2): 199-218.

Booth, J. A., A. Farrell, \& S. P. Varano. (2008). Social control, serious delinquency, and risky behaviors: A gendered analysis. Crime \& Delinquency 54: 423-456.

Bottcher, J. (2001). Social practices of gender: How gender relates to delinquency in the everyday lives of high-risk youth. Criminology, 39: 893-932.

Brody, L. R. \& Hall, J. A. (2000). Gender, emotion, and expression. In M. Lewis \& J. M. Haviland-Jones (Eds.), Handbook of emotions (pp. 338-349). New York: The Guilford Press.

Broidy, L. M. (2001). A test of general strain theory. Criminology, 39, 9-33.

Broidy, L. M. \& Agnew, R. (1997). Gender and crime: A general strain theory perspective. Journal of Research in Crime and Delinquency, 34, 275-306.

Burt, C. H. \& Clay-Warner, J. (2004). Not just 'rogue males:' Gender identity in general strain theory. Paper presented at the annual meeting of the American Society of Criminology, Nashville, TN.

Burton, V. S., F. T. Cullen, D. T. Evans, L. F. Alarid, \& R. G. Dunaway. (1998). Gender, selfcontrol, and crime. Journal of Research in Crime and Delinquency 35: 123-147.

Buss, D.M. \& Schmitt, D.P. (2011). Evolutionary psychology and feminism. Sex Roles. 64:768787.

Campbell, A. (1993). Men, Women and Aggression. New York: Basic Books.

Campbell, A. (2006). Sex differences in direct aggression: What are the psychological mediators? Aggression and Violent Behavior 11:237-264. 
Cohn, E. S., D. Bucolo, C. J. Rebellon, \& K. Van Gundy. (2010). An integrated model of legal and moral reasoning and rule-violating behavior: The role of legal attitudes. Law and Human Behavior 34:295-309.

Coleman, P. T., Goldman, J. S., \& Kugler, K. (2009). Emotional intractability: Gender, anger, aggression and rumination in conflict. International Journal of Conflict Management, 20, 113-131.

Costello, B. J. \& H. J. Mederer. (2003). A control theory of gender difference in crime and delinquency. In C. L. Britt and M.R. Gottfredson (Eds.), Control Theories of Crime and Delinquency (pp. 77-107). New Brunswick, NJ: Transaction.

Crosnoe, R. K., G. Erickson, \& S. M. Dornbusch. (2002). Protective functions of family relationships and school factors on the deviant behavior of adolescent boys and girls. Youth and Society, 33: 515-544.

DeCoster, S., Heimer, K., \& Cumley, S.R. (2013). Gender and theories of delinquency. The Oxford handbook of criminological theory, pp. 313-330, edited by Francis T. Cullen and Pamela Wilcox. New York: Oxford University Press.

Eagly, A. H. \& V. J. Steffen. (1986). Gender and aggressive behavior: A meta-analytic review of the social psychological literature. Psychological Bulletin 100(3):309-330.

Eitle, D. J. \& R. J. Turner. (2002). Exposure to community violence and young adult crime: The effects of witnessing violence, traumatic victimization, and other stressful life events. Journal of Research in Crime and Delinquency, 39: 214-237.

Else-Quest, N. M., A. Higgins, C. Allison, \& L. C. Morton. (2012). Gender differences in selfconscious emotional experience: A meta-analysis. Psychological Bulletin 138(5): 947-981.

Esbensen, F-A., D. Peterson, T. J. Taylor, \& A. Freng. (2010).Youth Violence: Sex and Race Differences in Offending, Victimization, and Gang Membership. Temple University Press.

Ferguson, T. J. (2000). Engendering gender differences in shame and guilt: Stereotypes, socialization, and situational pressures. In Gender and Emotion: Social Psychological Perspectives, edited by Agneta H. Fischer, pp. 254-276. New York: Cambridge.

Finley, N. J. \& H. G. Grasmick. (1985). Gender roles and social control. Sociological Spectrum 5:317-330.

Frost, D. W. \& Averill, J. R. (1982). Differences between men and women in the everyday experience of anger. In J. R. Averill (Ed.), Anger and aggression (pp.281-315). New York: Springer-Verlag.

Gilligan, C. (1982). In a different voice: Psychological theory and women's development. Cambridge, MA: Harvard University Press. 
Giordano, P. C., S. A. Cernkovich, and M. D. Pugh. (1986). Friendships and delinquency. American Journal of Sociology, 91: 1170-1202.

Gottfredson, Michael R., and Travis Hirschi. (1990). A General Theory of Crime. Stanford, CA: Stanford University Press.

Grasmick, H. G., Blackwell, B.S., \& Bursik, R.J. Jr. (1993). Changes in the sex patterning of perceived threats of sanctions. Law \& Society Review, 27, 679-705.

Grasmick, H. G., \& R. J. Bursik R. J. (1990). Conscience, significant others, and rational choice: Extending the deterrence model. Law \& Society Review, 24, 837-861.

Grasmick, H. G., Tittle, C. R., Bursik, R. J. Jr., \& Arneklev, B. J. (1993). Testing the core implications of Gottredson and Hirschi's general theory of crime. Journal of Research in Crime and Delinquency, 30(1), 5-29.

Hagan, John. (1989). Structural Criminology. Rutgers University Press.

Hagan, J., A. R. Gillis, and John Simpson. (1990). Clarifying and Extending Power-Control Theory. American Journal of Sociology 95 (4): 1024-1037.

Hagan, J., J. Simpson, \& A. R. Gillis. (1987). Class in the household: A power-control theory of gender and delinquency. American Journal of Sociology 92 (4): 788-816.

Hay, C. (2003). Family strain, gender, and delinquency. Sociological Perspectives, 46, 107-135.

Heimer, K. (1996). Gender, interaction, and delinquency: Testing a theory of differential social control. Social Psychology Quarterly, 59, 39-61.

Heimer, K. \& S. De Coster. (1999). The gendering of violent delinquency. Criminology, 37, 277318.

Higgins, G. E. \& R. Tewksbury. (2006). Sex and self-control theory: The measures and causal model may be different. Youth \& Society 37: 479-503.

Hirschi, Travis. (1969). Causes of Delinquency. Berkley, CA: University of California Press.

Jang, S. J. (2007). Gender differences in strain, negative emotions, and coping behaviors: A general strain theory approach. Justice Quarterly, 24, 523-553.

Jang, S. J. \& Johnson, B. R. (2005). Gender, religiosity, and reactions to strain among African Americans. The Sociological Quarterly, 46, 323-357.

Jansz, J. (2000). Masculine identity and restrictive emotionality. In A. H. Fischer (Ed.), Gender 
and emotion: Social psychological perspectives (pp. 166-188). Cambridge, UK: Cambridge University Press.

Jensen, G. F. (2003). Gender Variation in Delinquency: Self-Images, Beliefs and Peers as Mediating Mechanisms. Pp. 151-178 in Social Learning and the Explanation of Crime: New Directions for a new century, edited by Ronald L. Akers and Gary F. Jensen. Piscataway, NJ: Transaction Publishers.

Jensen, G. F. \& K. Thompson. (1990). What's class got to do with it? A further examination of power-control theory. American Journal of Sociology 95 (4): 1009-1023.

Kaplan, H. B. \& Xiaoru Liu. (2006). A longitudinal analysis of mediating variables in the drug use-dropping out relationship. Criminology, 32(3), 415-439.

Kemper, T.D. (1987). How many emotions are there? Wedding the social and the autonomic components. American Journal of Sociology. 93:263-289.

Kemper, T.D. \& Collins, R. (1990). Dimensions of microinteraction. American Journal of Sociology. 96:32-68.

LaGrange, T. C., \& R. A. Silverman. (1999). Low self-control and opportunity: Testing the general theory of crime as an explanation for gender differences in delinquency. Criminology 37: 41-72.

Lapsley, D.K. (1996). Moral psychology. Boulder, CO: Westview.

Lauritsen, J. L., K. Heimer, and J. P. Lynch. (2009). Trends in the gender gap in violent offending: New evidence from the National Crime Victimization Survey. Criminology, 47, 361-399.

Liu, X. \& Kaplan, H. B. (1999). Explaining the gender difference in adolescent delinquent behavior: A longitudinal test of mediating mechanisms. Criminology, 37, 195-215.

Lo, Celia C. \& Hua Zhong. (2006). Linking crime rates to relationship factors: The use of gender-specific data. Journal of Criminal Justice, 34: 317-329.

Long, J. S. (1997). Regression models for categorical and limited dependent variables. Thousand Oaks, CA: Sage Publications.

MacKinnon, D. P., Warsi, G., \& Dwyer, J. H. (1995). A simulation study of mediated effect measures. Multivariate Behavioral Research, 30, 41-62.

Manasse, M. \& Ganem, N. M. (2009). Victimization as a cause of delinquency: The role of depression and gender. Journal of Criminal Justice, 37, 371-378.

McCarthy, B., D. Felmlee, and J. Hagan. (2004). Girl friends are better: Gender, friends, and crime among school and street youth. Criminology, 42: 805-835. 
Mears, D. P., Ploeger, M., \& Warr, M. (1998). Explaining the gender gap in delinquency: Peer influence and moral evaluations of behavior. Journal of Research in Crime and Delinquency, $35,251-266$.

Messerschmidt, J. W. (1993). Masculinities and Crime. Lanham, MD: Rowman and Littlefield.

Mirowsky, J. \& Ross, C. E. (1995). Sex differences in distress: Real or artifact? American Sociological Review, 60, 449-468.

Mirowsky, J. \& Ross, C. E. (2003). Social Causes of Psychological Distress. Hawthorne, NY: Aldine De Gruyter.

Moffitt, T. E., Caspi, A, Rutter, M., \& Silva, P. A. (2001). Sex differences in antisocial behavior: Conduct disorder, delinquency and violence in the Dunedin Longitudinal Study. Cambridge, UK: Cambridge University Press.

Mullins, C., Wright, R., \& Jacobs, B. (2004). Gender, streetlife, and criminal retaliation. Criminology, 42, 911-940.

Ostrowsky, M. K. \& Messner, S. F. (2005). Explaining crime for a young adult population: An application of general strain theory. Journal of Criminal Justice, 33, 463-476.

Paternoster, R., Brame, R., Mazerolle, P., \& Piquero, A. (1998). Using the correct statistical test for the equality of regression coeffecients. Criminology, 36, 859-866.

Piquero, Nicole L., Gover, A. R., MacDonald, J. M., \& Piquero, A. R. (2005). The influence of delinquent peers on delinquency: Does gender matter? Youth \& Society, 36(3), 251- 275.

Piquero, N. L. \& Sealock, M. D. (2004). Gender and general strain theory: A preliminary test of Broidy and Agnew's gender/GST hypotheses. Justice Quarterly, 21, 125-158.

Piquero, N. L., Fox, K., Piquero, A.R., Capowich, G., \& Mazerolle, P. (2010). Gender, general strain theory, negative emotions, and disordered eating. Journal of Youth and Adolescence, 39, 380-392.

Preston, P. (2006). Marijuana use as a coping response to psychological strain: Racial, ethnic, and gender differences among young adults. Deviant Behavior, 27: 397-421.

Radloff, L.S. (1977). The CES-D scale: A self-report depression scale for research in the general population. Applied Psychological Measurement 1:385-401.

Rebellon, C. J., M. A. Straus, \& R. Medeiros. (2008). Self-control in global perspective: An empirical assessment of Gottfredson and Hirschi's general theory within and across 32 national settings. European Journal of Criminology 5: 331-362. 
Schwartz, J. \& B. D. Rookey. (2008). The narrowing gender gap in arrests: Assessing competing explanations using self-report, traffic fatality, and official data on drunk driving, 1980-2004. Criminology 46: 637-671.

Shields, S. A. (1995). The role of emotion beliefs and values in gender development. In N. Eisenberg (Ed.), Review of personality and social psychology (pp. 212-232). Thousand Oaks, CA: Sage.

Shirtcliff, E.A., Vitacco, M.J., Graf, A.R., Gostisha, A.J., Merz, J.L., Zahn-Waxler, C. (2009). Neurobiology of empathy and callousness: Implications for the development of antisocial behavior. Behavioral Science and the Law. 27:137-171.

Sigfusdottir, I., Farkas, G., \& Silver, E. (2004). The role of depressed mood and anger in the relationship between family conflict and delinquent behavior. Journal of Youth and Adolescence, 33: 509-522.

Smith, C. A. \& Lazarus, R. S. (1993). Appraisal components, core relational themes, and the emotions. Cognition and Emotion, 7: 295-323.

Smith, D. A. \& R. Paternoster. (1987). The gender gap in theories of deviance: Issues and evidence. Journal of Research in Crime \& Delinquency 24: 140-172.

Smith, D. A. \& C.A. Visher. (1980). Sex and involvement in deviance/crime: A quantitative review of the empirical literature. American Sociological Review, 45: 691-701.

Steffensmeier, D. \& J. Schwartz. (2009). Trends in girls' delinquency and the gender gap: Statistical assessment of diverse sources. In M.A. Zahn (Ed.), The Delinquent Girl (pp. 5083). Philadelphia, PA: Temple University Press.

Steffensmeier, D., J. Schwartz, H. Zhong, \& J. Ackerman. (2005). An assessment of recent trends in girls' violence using diverse longitudinal sources: Is the gender gap closing? Criminology 43: 355-405.

Stevens, T., M. Morash, \& S. Park. (2011). Late-adolescent delinquency: Risks and resilience for girls differing in risk at the start of adolescence. Youth \& Society 43: 1433-1458.

Sutherland, E. H. (1947). Principles of criminology ( $4^{\text {th }}$ ed.). Philadelphia, PA: J.B. Lippincott.

Svensson, R. (2003). Gender differences in adolescent drug use: The impact of parental monitoring and peer deviance. Youth \& Society 34: 300-329.

Svensson, R., F. W. Weerman, L.J.R. Pauwels, G.J.N. Bruinsma, \& W. Bernasco. (2013). Moral emotions and offending: Do feelings of anticipated shame and guilt mediate the effect of socialization on offending?" European Journal of Criminology 10(1):22-39. 
Tangney JP, Stuewig J and Mashek DJ. (2007). Moral emotions and moral behavior. Annual Review of Psychology 58: 345-372.

Thompson, S. (1999). Attribution. In D. Levinson, J. J. Ponzetti, \& P. F. Jorgenson (Eds.), Encyclopedia of human emotions (pp. 92-99). New York: Macmillan.

Thornberry, T. P., A. Lizotte, M. Krohn, M. Farnworth, and S. J. Jang. (1991). Testing interactional theory: An examination of reciprocal causal relationships among family, school, and delinquency. Journal of Criminal Law and Criminology, 82: 3-35.

Tibbetts, S.G. (2003). Self-conscious emotions and criminal offending. Psychological Reports, 93:101-126.

Tittle, C. R., D. A. Ward, \& H. G. Grasmick. (2003). Gender, age, and crime/deviance: A challenge to self-control theory. Journal of Research in Crime and Delinquency 40: 426-453.

Udry, J.R. (2000). Biological limits of gender construction. American Sociological Review. 65:443-457.

Van Gundy, K. (2002). Gender, the assertion of autonomy, and the stress process in young adulthood. Social Psychology Quarterly, 65: 346-363.

Wade, L. (2013). The new science of sex differences. Sociological Compass. 7:278-293.

Warr, M. (2002). Companions in Crime: The Social Aspect of Criminal Conduct. Cambridge: Cambridge University Press.

Wikstrom, P. H. (2004). Crime as alternative: Towards a cross-level situational action theory of crime causation. In Joan McCord (ed.) Beyond Empiricism: Institutions and Intentions in the Study of Crime. New Brunswick, NJ: Transaction, 1-37.

Wikstrom, P. H. (2006). Individuals, settings and acts of crime: situational mechanisms and the explanation of crime. In: Wikstrom P-O H, Sampson RJ (eds) The Explanation of Crime: Context, Mechanisms and Development. Cambridge: Cambridge University Press, 61-107.

Wikstrom, P. H. \& Svensson, R. (2010). When does self-control matter? The interaction between morality and self-control in crime causation. European Journal of Criminology, 7, 5: 395410 .

Wikstrom, P. H., Tseloni, A., Karlis, D. (2011). Do people comply with the law because they fear getting caught? European Journal of Criminology, 8, 5: 401-420.

Zimmerman, G. M., \& Messner, S. F. (2010). Neighborhood context and the gender gap in adolescent violent crime. American Sociological Review, 75(6): 958-980. 
Table 1. Descripti ve Stati sti cs

\begin{tabular}{|c|c|c|c|c|c|c|c|c|c|c|}
\hline & \multicolumn{5}{|c|}{ Males } & \multicolumn{5}{|c|}{ Females } \\
\hline & $\mathbf{N}$ & Min & Max & Mean & SD & $\mathbf{N}$ & Min & Max & Mean & SD \\
\hline Delinquency & 336 & 0.0 & 9.0 & 1.26 & 2.02 & 471 & 0.0 & 7.0 & 0.79 & $1.41^{* *}$ \\
\hline Drug Use & 336 & 0.0 & 4.0 & 0.59 & 1.04 & 471 & 0.0 & 4.0 & 0.59 & 0.99 \\
\hline Age & 389 & 11.0 & 17.0 & 13.67 & 1.62 & 546 & 11.0 & 17.0 & 13.76 & 1.60 \\
\hline SES & 380 & 1.0 & 6.0 & 3.63 & 1.24 & 535 & 1.0 & 6.0 & 3.52 & 1.28 \\
\hline White & 385 & 0.0 & 1.0 & 0.79 & 0.41 & 543 & 0.0 & 1.0 & 0.80 & 0.40 \\
\hline Unfairness & 324 & 0.0 & 3.0 & 0.64 & 0.55 & 455 & 0.0 & 3.0 & 0.62 & 0.51 \\
\hline Life Events & 324 & 0.0 & 13.0 & 1.76 & 2.28 & 451 & 0.0 & 13.0 & 1.94 & 2.10 \\
\hline Anger & 326 & 0.0 & 4.0 & 1.71 & 0.88 & 457 & 0.0 & 4.0 & 1.76 & 0.82 \\
\hline Depression & 323 & 0.2 & 2.8 & 0.94 & 0.39 & 450 & 0.1 & 2.7 & 1.04 & $0.46^{* *}$ \\
\hline Parental Rules & 389 & 0.0 & 25.0 & 14.99 & 6.33 & 544 & 0.0 & 25.0 & 15.00 & 5.94 \\
\hline Parental Monitoring & 324 & 0.0 & 4.0 & 3.02 & 0.97 & 457 & 0.0 & 4.0 & 3.37 & $0.85^{* *}$ \\
\hline Parental Consequences & 385 & 1.6 & 3.4 & 2.58 & 0.33 & 537 & 1.2 & 4.0 & 2.59 & 0.35 \\
\hline Low Self-control & 389 & 0.0 & 3.0 & 1.31 & 0.54 & 548 & 0.0 & 3.0 & 1.18 & $0.53^{* *}$ \\
\hline Peer Delinquency & 388 & 0.0 & 2.9 & 0.29 & 0.49 & 548 & 0.0 & 3.0 & 0.21 & $0.38^{* *}$ \\
\hline Peer Drug Use & 388 & 0.0 & 3.0 & 0.40 & 0.70 & 548 & 0.0 & 3.0 & 0.45 & 0.73 \\
\hline Atti tudes (Delinquency) & 390 & 0.0 & 3.0 & 0.28 & 0.47 & 548 & 0.0 & 2.8 & 0.21 & $0.37^{*}$ \\
\hline Atti tudes (Drug Use) & 390 & 0.0 & 3.0 & 0.36 & 0.65 & 548 & 0.0 & 3.0 & 0.35 & 0.60 \\
\hline Guilt (Delinquency) & 388 & 1.0 & 6.0 & 4.08 & 1.64 & 546 & 1.0 & 6.0 & 4.56 & $1.55^{* *}$ \\
\hline Guilt (Drug Use) & 387 & 1.0 & 6.0 & 4.74 & 1.88 & 543 & 1.0 & 6.0 & 4.96 & 1.77 \\
\hline
\end{tabular}


Table 2. Exposure and Vulnerability Explanati onsfor the Gender Gap in Delinquency: Negati ve Binomial Esti mates

\begin{tabular}{|c|c|c|c|c|c|c|c|c|c|c|c|c|c|c|c|c|c|}
\hline & $\begin{array}{c}\text { (1) } \\
\text { Pooled }\end{array}$ & $\begin{array}{c}\text { (2) } \\
\text { Pooled }\end{array}$ & $\begin{array}{c}\text { [3) } \\
\text { Pooled }\end{array}$ & $\begin{array}{c}{[4]} \\
\text { Pooled }\end{array}$ & $\begin{array}{c}\text { (5) } \\
\text { Pooled }\end{array}$ & $\begin{array}{c}(6) \\
\text { Pooled }\end{array}$ & $\begin{array}{c}\text { (7) } \\
\text { Pooled }\end{array}$ & ' & $\begin{array}{c}\text { (8) } \\
\text { Males }\end{array}$ & $\mathrm{Fer}$ & $\begin{array}{l}\text { (9) } \\
\text { emales }\end{array}$ & $M^{1}$ & $\begin{array}{c}\text { (10) } \\
\text { Males }\end{array}$ & $\mathrm{Fe}$ & $\begin{array}{l}\text { (11) } \\
\text { emales }\end{array}$ & $\begin{array}{c}\text { Gender } \\
\text { Diff erence (z) } \\
\text { [Models } 8 \& 9 \text { ] }\end{array}$ & $\begin{array}{c}\text { Gender } \\
\text { Diff erence (z) } \\
\text { [Models 10\& 11] }\end{array}$ \\
\hline Female & $-.61(.15) * *$ & $-.66(.13) * *$ & $-.32(.13) *$ & $-.30(.13)^{*}$ & $-.26(.14)$ & $-.31(.12) *$ & $-.22(.12)$ & & & & & & & & & & \\
\hline Age & $.20(.05)^{* *}$ & $.19(.04) * *$ & $.13(.04)^{* *}$ & $.00(.04)$ & $.08(.04)$ & $.08(.04)$ & $.06(.04)$ & .08 & $(.06)$ & .08 & $(.06)$ & .06 & $(.06)$ & .07 & $(.06)$ & .00 & -.15 \\
\hline SES & $-.15(.05) * *$ & $-.06(.05)$ & $-.03(.05)$ & $-.11(.05) *$ & $-.12(.05) *$ & $-.01(.05)$ & $-.01(.05)$ & .10 & $(.07)$ & -.10 & $(.06)$ & .10 & $(.07)$ & -.10 & $(.06)$ & 2.17 & 2.21 \\
\hline white & $-.12(.18)$ & $.06(.16)$ & $.06(.16)$ & $.03(.16)$ & $.05(.16)$ & $.18(.15)$ & $.21(.14)$ & .26 & $(.21)$ & .10 & $(.20)$ & .29 & $(.20)$ & .14 & $(.20)$ & .55 & .52 \\
\hline Unfairness & & $.31(.14) *$ & & & & $.15(.13)$ & $.09(.12)$ & -.05 & $(.16)$ & .36 & (.19) & -.18 & $(.16)$ & .37 & $(.18)^{*}$ & -1.65 & -2.27 \\
\hline Life Events & & .20 (.03) ** & & & & $.11(.03) * *$ & $.12(.03) * *$ & .15 & $(.04) * *$ & .07 & $(.04)$ & .19 & $(.04) * *$ & .07 & $(.04)$ & 1.41 & 1.93 \\
\hline Anger & & $.27(.08) *$ & & & & $.16(.08) *$ & $.14(.07)$ & .09 & $(.10)$ & .21 & (.11) & .10 & $(.10)$ & .19 & (.11) & -.81 & -.58 \\
\hline Depression & & $.21(.17)$ & & & & $.16(.16)$ & $.12(.15)$ & .30 & $(.25)$ & .00 & $(.20)$ & .21 & $(.24)$ & .02 & $(.20)$ & .94 & .61 \\
\hline Parental Rules & & & $-.02(.01) *$ & & & $.00(.01)$ & $.00(.01)$ & .01 & $(.02)$ & -.01 & $(.01)$ & .02 & $(.02)$ & -.01 & $(.02)$ & .89 & 1.39 \\
\hline Parental Monitoring & & & $-.48(.07)^{* *}$ & & & $-.30(.07) * *$ & $-.26(.07)^{* *}$ & -.28 & $(.10) * *$ & -.33 & $(.10) * *$ & -.23 & $(.09) *$ & -.30 & (.10) ** & .35 & .55 \\
\hline Parental Consequences & & & $-.07(.20)$ & & & $.01(.19)$ & $.06(.18)$ & .20 & $(.26)$ & -.14 & $(.26)$ & .28 & $(.26)$ & -.16 & $(.25)$ & .92 & 1.23 \\
\hline Low Self-control & & & $.93(.13) * *$ & & & $.53(.13)^{* *}$ & $.44(.12) * *$ & .20 & $(.17)$ & .80 & $(.19)^{* *}$ & .22 & $(.16)$ & .61 & $(.19) * *$ & -2.35 & -1.59 \\
\hline Peer Delinquency & & & & $1.09(.18) * *$ & & $.54(.17) * *$ & $.41(.16) * *$ & .60 & $(.21) * *$ & .48 & $(.25)$ & .47 & $(.19)$ * & .34 & $(.25)$ & .37 & .43 \\
\hline Atti tudes (Delinquency) & & & & $.92(.17) * *$ & & $.33(.16)^{*}$ & $.10(.16)$ & .38 & $(.20)$ & .28 & $(.25)$ & .11 & $(.20)$ & .06 & $(.26)$ & .31 & .15 \\
\hline Guilt (Delinquency) & & & & & $-.45(.04) * *$ & & $-.21(.04) * *$ & & & & & .24 & $(.06) * *$ & -.20 & $(.06) * *$ & & -.48 \\
\hline Constant & $-1.91(.67) * *$ & $-3.63(.62) * *$ & $-1.01(.89)$ & $-.17(.62)$ & $1.18(.68)$ & $-2.01(.89) *$ & $-1.00(.90)$ & $-2.90(1) x)($ & (1.19) * & -1.85( & $(1.30)$ & $-1.95(1$ & $(1.17)$ & -.51 & $(1.34)$ & & \\
\hline$\alpha$ & $2.16(.25) * *$ & $1.20(.17) * *$ & $1.07(.16) * *$ & $1.25(.18) *$ & $1.35(.19) * *$ & $.72(.13) * *$ & $.61(.12) * *$ & .64 & $(.17) * *$ & .58 & $(.17) * *$ & .52 & $(.15) * *$ & .51 & (.16) ** & & \\
\hline u & -843.74 & -782.99 & -768.36 & -788.13 & -793.89 & -732.45 & -721.13 & -353 & 3.04 & -368 & 8.08 & -345.7 & 5.73 & -362 & 2.97 & & \\
\hline $\mathbf{N}$ & 655 & 655 & 655 & 655 & 655 & 655 & 655 & 268 & 68 & 387 & & 268 & 68 & 38 & & & \\
\hline
\end{tabular}


Figure 1. The Direct and Indirect Effects of Gender on Delinquency (Guilt Omitted)

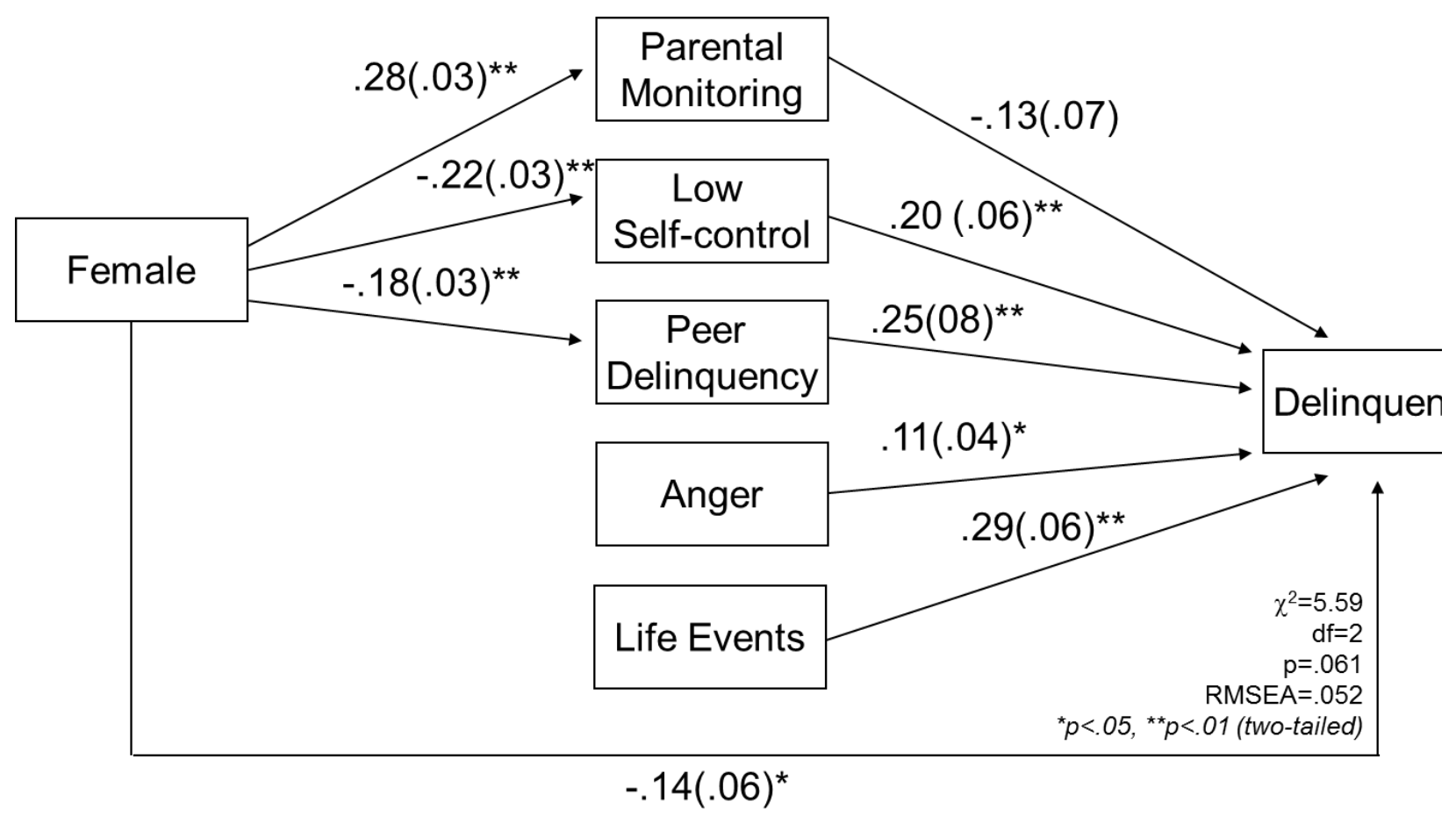


Figure 2. The Direct and Indirect Effects of Gender on Delinquency (Guilt Included)

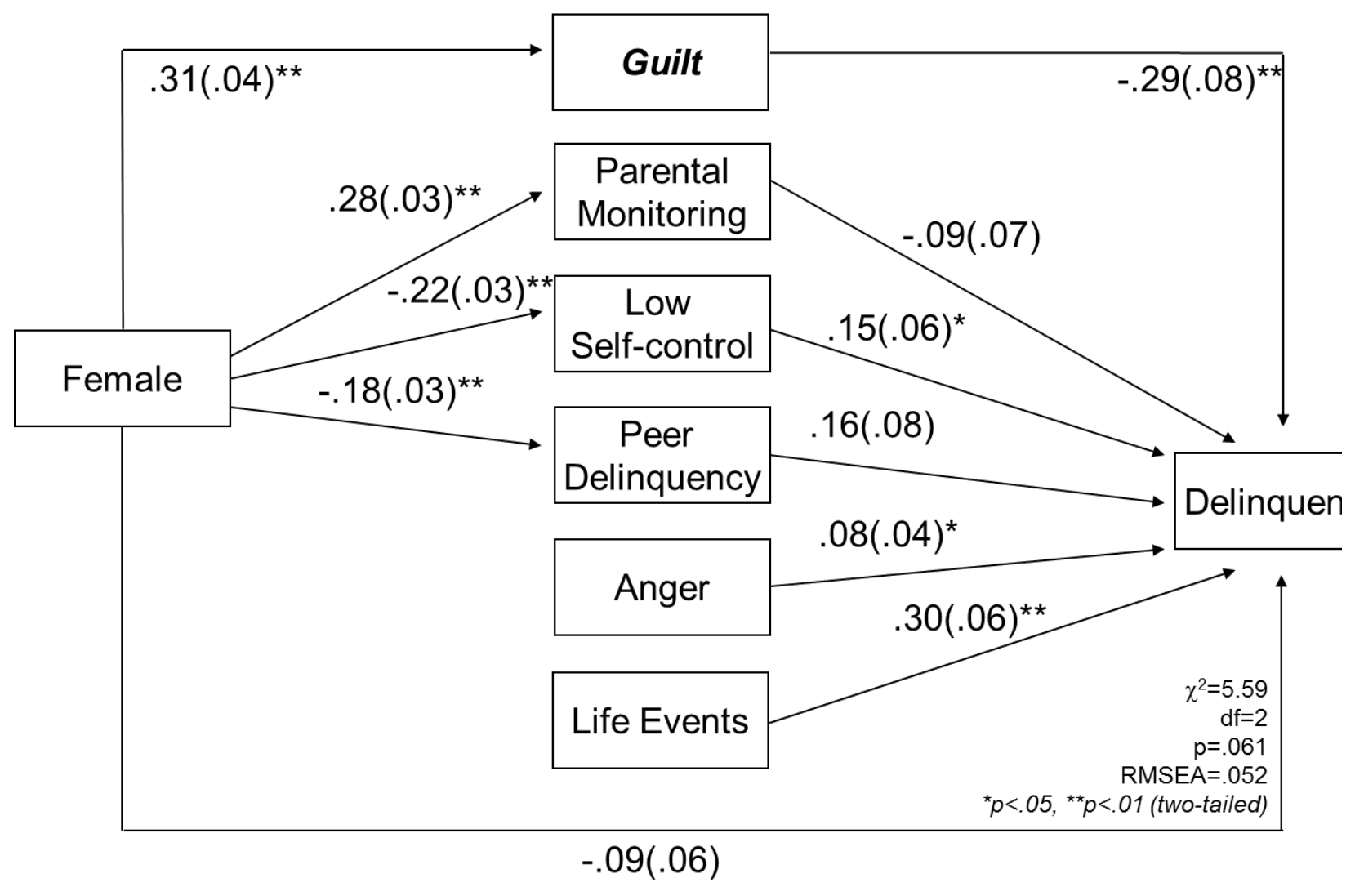




\section{Appendix A. Scale/Index Items}

Delinquency ( $0=\mathrm{No}, 1=\mathrm{Yes})$

Theft $<\$ 50$ (not from store)

Theft $>\$ 50$ (not from store)

Motor Vehicle Theft

Broken into Building

Sold or Held Stolen Goods

Shoplifting (from store)

Damaged others' property

Hit or threatened to hit

Used force to get something from someone

Drug Use (0=No, 1=Yes)

Cigarettes

Alcohol

Marijuana

Other Drugs

Unfairness (0=Very Fair, 1=Somewhat fair, 2=Somewhat unfair, 3=Very unfair)

Mother (or female guardian)

Father (or male guardian)

Your friends

Other kids at school

Teachers

Life Events ( $0=$ No, $1=$ Yes)

Parent divorce/separation

Parent fired

Failed a class

Close friendship ended

Romantic breakup

Move to new neighborhood

Home broken into

Parents kicked you out of house

Victim of theft

Victim of property damage 
Victim of violent attack

Kids scared you, were mean to you, called you names

Someone close used drugs/alcohol enough to cause your problems for your family

Grownups scared you, were mean to you, called you names

Anger ( $0=$ Never, 1=A few times, $2=$ Once or twice a month, 3=Once or twice a week, 4=Almost every day)

Mother (or female guardian)

Father (or male guardian)

Your friends

Other kids at school

Teachers

Depression ( $0=$ Not at all, 1=Occasionally, 2=Frequently, 3=Almost all the time)

Bothered by things that usually don't bother me

Didn't feel like eating

Felt I was just as good as other people (reversed)

Had trouble keeping my mind on what I was doing

Felt everything I did was an effort

Felt hopeful about the future (reversed)

Felt I was a failure

Felt fearful

My sleep was restless

I was happy (reversed)

I talked less than usual

I felt lonely

People were unfriendly

I enjoyed life (reversed)

I felt sad

Parental Rules ( $0=\mathrm{No}, 1=\mathrm{Yes})^{\mathrm{iii}}$

What time you come home?

Where you hang out?

Doing your homework?

Doing chores or jobs at home?

Having friends over?

The food you eat?

Fighting with other kids?

Drinking alcohol?

Who you hang out with?

When you go to bed?

Cleaning your room? 
What you watch on TV?

What you do on the internet?

What music you listen to?

What movies you watch?

Talking on the phone?

How you spend money?

What clothes you wear?

Family meals?

Religion or worship?

Dating?

Working for pay?

The language you use?

Smoking?

Using drugs?

Parental Monitoring ( $0=$ Never, $1=$ Rarely, $2=$ =Sometimes, 3=Usually, 4=Always)

Tell your parents where you will be after school

Tell your parents where you're really going when you go out

Talk with your parents about plans with friends

How often do parents ask where you are going

If you'll be home late are you expected to call your parents

Tell your parents who you are going out with

Parental Consequences ( $1=$ Strongly agree, 2=Agree, 3=Disagree, 4=Strongly disagree)

If my parents tell me to do something, they mean it

If my parents find out I disobeyed them, there are definitely consequences

Sometimes parents threaten to punish me, but then don't punish me (reversed)

I can break my parents' rules without consequences (reversed)

Sometimes I don't know how my parents will react when I break their rules (reversed)

Low Self-control (Grasmick et al., 1993, 0=Strongly disagree, 1=Disagree, 2=Agree, 3=Strongly agree)

I often act fast without thinking

I don't give much thought and effort to thinking about the future

I often do whatever brings me pleasure here and now, even at the cost of some distant goal

I am more concerned with what happens to me in the short run than in the long run

I often try to avoid projects that I know will be difficult

When things get hard, I tend to quit or withdraw

The things in life that are easiest to do bring me the most pleasure

I dislike hard tasks that stretch my abilities to the limit

I like to test myself every now and then by doing something a little risky

Sometimes I will take a risk just for the fun of it 
I sometimes find it exciting to do things for which I might get in trouble

Excitement and adventure are more important to me than security

If I had a choice, I would almost always rather do something physical than something mental

I almost always feel better when I am on the move than when I am sitting and thinking

I like to get out and do things more than I like to read or think about ideas

I seem to have more energy and a greater need for activity than most kids my age

I try to look out for myself first, even if it means making things difficult for others

I'm not very sensitive to other people when they are having a problem

If things I do upset people, it's their problem not mine

I will try to get things I want even when I know it's causing problems

I lose my temper easily

Often when I'm angry at people, I feel more like hurting them than talking to them about why I'm angry

When I'm angry other people better stay away from me

When I have a serious argument with someone, it's usually hard for me to talk calmly about it without getting upset

Peer Offending (0=None, 1=A few, 2=Some, 3=Many)

Attitudes (0=Strongly Disapprove, 1=Disapprove, 2=Approve, 3=Strongly Approve)

Guilt if no one found out (1=not at all guilty, 6=Very guilty)

Theft $<\$ 5$

Theft $>\$ 50$

Punching someone who had not hit you first

Smoked Marijuana

\footnotetext{
' We note that our analyses include multiple scales derived from each of the leading micro-level theories. In the analyses presented, we have opted against combining scales from a given theory for both theoretical and empirical reasons. First, general strain theory explicitly argues that different strains and/or emotions may have different effects on offending, and that the strains/emotions that exert the greatest effects may vary by gender (Agnew, 2006; Broidy and Agnew, 1997). Second, as discussed previously, empirical research concerning control theory sometimes finds that direct controls like parental monitoring remain independently associated with offending even after adjusting statistically for self-control (e.g., Rebellon et al., 2008). At the same time, on the suggestion of one reviewer, we ran an alternative set of analyses in which we standardized each of a given theory's measures before then combining them into one single scale. Results of these analyses were substantively very similar to those presented herein, yielding the same implications for the importance of guilt as part of the explanation for the gender gap in offending.
} 
ii The absolute values of all bivariate correlations among predictor variables were below .70, with the highest two being that between attitudes and delinquent peers (.54) and that between attitudes and guilt (.54). Variance inflation factors based on OLS results yielding substantively similar conclusions were all well below 10 , with the highest being 1.80 for attitudes. These results suggest to us that multicollinearity does not pose a problem for our interpretation of substantive results.

iii Several of these parental rules concern behaviors directly related to delinquency and one reviewer suggested we examine whether omitting these items from our parental rules index altered the results. We ran analyses with an alternative parental rule index as per this suggestion and substantive results remained the same. 